\title{
The Relationship between Polar Vortex and Ozone Depletion in the Antarctic Stratosphere during the Period 1979-2016
}

\author{
Yu Zhang, ${ }^{1,2}$ Jing Li, ${ }^{2,3,4}$ and Libo Zhou ${ }^{5}$ \\ ${ }^{1}$ College of Ocean and Meteorology, Guangdong Ocean University, Zhanjiang, China \\ ${ }^{2}$ Department of Atmospheric and Environmental Sciences, University at Albany, State University of New York, Albany, NY, USA \\ ${ }^{3}$ Nansen-Zhu International Research Centre, Institute of Atmospheric Physics, Chinese Academy of Sciences, Beijing, China \\ ${ }^{4}$ University of Chinese Academy of Sciences, Beijing, China \\ ${ }^{5}$ LAPC \& LAOR, Institute of Atmospheric Physics, Chinese Academy of Sciences, Beijing, China
}

Correspondence should be addressed to Libo Zhou; zhoulibo@mail.iap.ac.cn

Received 25 May 2017; Revised 14 July 2017; Accepted 27 July 2017; Published 29 August 2017

Academic Editor: Dong Guo

Copyright (c) 2017 Yu Zhang et al. This is an open access article distributed under the Creative Commons Attribution License, which permits unrestricted use, distribution, and reproduction in any medium, provided the original work is properly cited.

As the most prominent feature of the polar stratosphere, polar vortex results in widespread changes in the climate system, especially in the ozone variation. In this study, the linkage between polar vortex and ozone depletion in Antarctic stratosphere during the period 1979-2016 is investigated; we calculated the averaged total column ozone within the polar vortex based on the vortex edge (-28.8 PVU PV contour) instead of the geographical region defined by latitude and longitude. Results from the spatial patterns of ozone and polar vortex suggest that the morphological changes of polar vortex can impact the horizontal distribution of ozone and the ozone within the polar vortex experiences a severe depletion in spring. The negative relationship between ozone and polar vortex in terms of vortex area, strength, and breakup time is significant with the correlation coefficients of $-0.57,-0.68$, and -0.76 , respectively. The breakup time of polar vortex plays an important role in the relation between polar vortex and ozone depletion with the highest-value correlation coefficient among three polar vortex parameters. Furthermore, the possible mechanism for this relationship is also discussed in this article.

\section{Introduction}

The ozone layer is well known as shielding the earth's surface from being damaged by ultraviolet radiation (UV), which decreases the incidence of skin cancer and other diseases of humans, animals, and plants $[1,2]$. In the stratosphere, the air temperature increases with altitude rising from lower than $-50^{\circ} \mathrm{C}$ to greater than $-20^{\circ} \mathrm{C}$ at the stratopause [3], which is associated with the absorption of solar ultraviolet radiation by highest mixing ratio of ozone in the stratosphere. The ozone is mostly produced from short-wave ultraviolet rays between 240 and $160 \mathrm{~nm}$, and the oxygen is continuously converted to ozone and back to oxygen by numerous photochemical reactions as previous studies described [4]. However, groundbased and satellite observations show a dramatic decrease in ozone over Antarctica during austral spring since the 1980s $[5,6]$.
Over the past three decades, hot topics including both the severity of Antarctic ozone depletion and the size of the Antarctic ozone hole have attracted more and more attention. The intense cyclonic vortices that form over the winter pole are one of the most prominent features of the stratospheric circulation [7-9]. The structures and dynamics of the "polar vortex" play a dominant role in the stratospheric circulations and couplings between the stratosphere and troposphere during winter and spring. For example, Thompson et al. [10] revealed that fluctuations of the polar vortex profoundly impact the mean temperature and the frequency of occurrence of extreme cold events throughout the Northern Hemisphere. Li et al. [11] also discussed the effect of Arctic polar vortex on spring vegetation growth in boreal Eurasia. Actually, the term "vortex" refers to the flow of air that helps to maintain the colder air in proximity with the poles [12]. A typical vortex is marked by strong circumpolar winds and 
cold temperatures in the interior of vortex region, which is recognized as the key ingredient in the destruction of ozone and the formation of the ozone hole in polar region [3]. Additionally, polar vortex is also a key to determining distribution of trace gases, in particular ozone [13]. Several studies have highlighted the close relationship between changes in polar vortex and ozone depletion in stratosphere $[14,15]$. For example, Hassler et al. [16] analyzed the October mean total column ozone data from four Antarctic stations and concluded that the total ozone recorded at Antarctic stations has been strongly affected by the state of polar vortex. Schoeberl and Hartmann [3] further revealed the chemical process in the polar vortex during winter and found that the temperature within the polar vortex falls low enough to form the polar stratospheric clouds of nitric acid trihydrate and ice, which can affect the conversion of chlorine from the inactive reservoir species to the radical species that attack ozone. In addition, the dynamical characteristics of polar vortex provide the substance isolation to favor the ozone hole development.

In this study, we primarily focus on investigating the relationship between polar vortex and ozone depletion in the Antarctic stratosphere during the period 1979-2016. The total column ozone is calculated over the whole Antarctic region $\left(60^{\circ}-90^{\circ}\right)$ in previous studies [17]. However, the polar vortex is not constant all year round. In general, polar vortex shrinks in polar summer and expands in polar winter. Therefore, we define a new algorithm calculating the averaged total column ozone within polar vortex instead of the geographical region to emphasize the relation between the polar vortex and ozone. Considering the profound influence of polar vortex on largescale weather and climate systems, there is a variety of polar vortex parameters to represent its features [18, 19]. Therefore, we also use three polar vortex parameters (polar vortex area, polar vortex strength, and polar vortex breakup time) in this study to present the comprehensive results.

The remainder of the paper is organized as follows. The data and methods employed are described in Section 2. The relationships between polar vortex and ozone depletion in spatial distribution and temporal variation are discussed, respectively, in Section 3, and discussion and conclusions are provided in Section 4.

\section{Data and Methods}

2.1. Data. The European Centre for Medium Range Weather Forecast's Interim reanalysis dataset $[20,21]$ for the period from 1979 to 2016 is used for calculation of some quantities such as potential vorticity in this study. The data used include the daily geopotential, wind speed, temperature, and the monthly total column ozone with the spatial resolution of $1.5^{\circ} \times 1.5^{\circ}$; all variables except total column ozone with 37 pressure levels (from $1000 \mathrm{hPa}$ to $1 \mathrm{hPa}$ ) are interpolated to the isentropic levels from 450 to $650 \mathrm{~K}$ (50 K intervals), spanning the low stratosphere in which the ozone number density has the maximum.

\subsection{Methods}

2.2.1. Polar Vortex Area. The Antarctic polar vortex in low stratosphere can be described by the potential vorticity (PV)
TABLE 1: Values of criterion PV contour used to define the edge of the Antarctic vortex.

\begin{tabular}{lccccc}
\hline Isentropic surface & $450 \mathrm{~K}$ & $500 \mathrm{~K}$ & $550 \mathrm{~K}$ & $600 \mathrm{~K}$ & $650 \mathrm{~K}$ \\
\hline Waugh's (PVU) & -23.0 & -27.0 & $/$ & -29.0 & $/$ \\
Ours (PVU) & -23.3 & -26.8 & -28.8 & -31.7 & -32.1 \\
\hline
\end{tabular}

on isentropic surfaces. The PV diagnostic method developed by McIntyre and Palmer [22] has been widely used in many vortex feature studies. In this study, we adopt the PV diagnostic method to estimate the area, intensity, and breakup time of polar vortex, as well as to calculate the mean total column ozone within the polar vortex. As the magnitude of PV increases dramatically with height, we use the modified PV to remove this difference [23]. The PV values are normalized by a factor $\left(\theta / \theta_{0}\right)^{-9 / 2}$, where $\theta$ is the potential temperature and $\theta_{0}=475 \mathrm{~K}$ is a reference potential temperature. How to determine the vortex edge is crucial in this study, and several methods to define the vortex edge have been developed, each of them having both advantages and disadvantages [24]. A vortex edge marked by sharp gradients in PV presents a barrier to isentropic mixing [25]. Therefore, the vortex edges are defined by the PV contours with the maximum PV gradients at each isentropic surface (from 450 to $650 \mathrm{~K}, 50 \mathrm{~K}$ intervals) in this study. The PV contour values are fixed on given isentropic surface based on the 38-year climatology (from 1979 to 2016), with calculating the zonal mean PV where the maximum meridional PV gradients exist in each longitude during all winters in Southern Hemisphere (June-July-August). The values used to describe the polar vortex edge are shown in Table 1, which are mostly consistent with those from NCEP datasets (1978-1998) by Waugh and Randel [26]. Due to the differences of period of interest and data sources, it is reasonable to see some differences between Waugh's result and ours. Therefore, the polar vortex area is defined as the area enclosed by the criterion PV contours.

2.2.2. Polar Vortex Strength. Since the polar vortex is surrounded by the strong circumpolar westerly winds, the polar vortex strength is defined as the averaged zonal wind speed along the vortex edge referring to criterion PV contour in this study, which is consistent with previous studies [10, 27-30].

2.2.3. Polar Vortex Breakup Time. The evolution of polar vortex can be divided into three stages: it forms in autumn, reaches maximum strength in mid-winter, and decays in later winter to spring [13]. In this study, the polar vortex breakup time is defined as the timing when the polar vortex area shrinks to less than $1 \%$ of the Earth surface area or $78.5^{\circ}$ equivalent latitude (the latitude of a zonal circle that encloses the same area as the vortex edge) as Manney et al. [31] described.

2.2.4. Total Column Ozone within the Polar Vortex. The ozone number density has the maximum in the low stratosphere (isentropic levels from $450 \mathrm{~K}$ to $650 \mathrm{~K}$ ), according to the ozone vertical distribution. We calculated the mean vortex edge from $450 \mathrm{~K}$ to $650 \mathrm{~K}$ and found that the mean edge is 
closest to the edge on $550 \mathrm{~K}$ isentropic surface. Therefore, we use the criterion PV contour (-28.8 PVU) on $550 \mathrm{~K}$ isentropic surface to calculate the averaged total column zone within the polar vortex.

2.2.5. Statistical Analysis Methods. In order to illustrate the relationships between polar vortex and ozone depletion, the linear regression, correlation, and composite difference analysis methods are adopted in this study with detrend data. The statistical significance is determined by Student's $t$-tests based on the assumption that the sample data are independent.

\section{Results}

3.1. Relationships between Polar Vortex and Ozone Depletion in Spatial Distribution. As mentioned above, the potential vorticity $(\mathrm{PV})$ on isentropic surface is a good indicator to describe the Antarctic polar vortex. Meanwhile, the ozone layer mainly lies in the low stratosphere (isentropic levels from $450 \mathrm{~K}$ to $650 \mathrm{~K}$ ) according to the ozone density vertical distribution. Therefore, $550 \mathrm{~K}$ isentropic level is selected to analyze the relationship between polar vortex and ozone depletion as the vortex edge on this surface is closest to the mean edge ranges from $450 \mathrm{~K}$ to $650 \mathrm{~K}$.

Figure 1 shows the climatology of monthly potential vorticity on $550 \mathrm{~K}$ isentropic surface. The black solid line is the criterion PV contour (-28.8 PVU), which represents the edge of polar vortex. Usually, the Antarctic polar vortex forms in late April and decays in November; it exists stably from May to October despite the large interannual variations [13]. Therefore, these 6 months are selected to analyze the Antarctic polar vortex in this study, and the pattern for each month is presented in Figures 1(a)-1(f), respectively. The climatological polar vortex presents a quasi-symmetric circle in each month, and the center is close to the South Pole. With the developing of polar vortex from May to August, the vortex area increases gradually and reaches the maximum in August. Meanwhile, the potential vorticity value in high latitudes increases significantly, and the gradient of potential vorticity near the vortex edge deepens dramatically. On the other hand, with the decay of polar vortex from August to October, the vortex area and the potential vorticity field present an opposite change.

Figure 2 shows the climatology of monthly zonal wind on $550 \mathrm{~K}$ isentropic surface. Results from May to October are presented in Figures 1(a)-1(f), respectively. It is obvious that the polar vortex is surrounded by a strong circumpolar westerly jet. In Section 2, we define the polar vortex strength as the averaged zonal wind along the vortex edge; this definition can accurately represent the intensity of vortex rotation features. The westerly jet strengthens with the expanding of polar vortex from May to August, and it reaches the maximum (more than $60 \mathrm{~m} / \mathrm{s}$ ) in August. The strong westerly jet favors less energy and mass transportation from the southern midlatitudes to Antarctic region. With lower temperature and less supplement of lower-latitude ozone, the Antarctic ozone depletion would become more severe. With the decay of polar vortex from September to October, the intensity of circumpolar jet decreases gradually consistent with the change of polar vortex area described above.

Figure 3 shows the spatial distributions of the 38 -year (1979-2016) total column ozone climatology. The vortex edge is used to distinguish the interior and exterior of vortex in calculation of averaged ozone in the next section. Results from May to October are presented in Figures 1(a)-1(f), respectively. With the development of polar vortex, the horizontal distribution of total column ozone changes gradually. The ozone difference between inside and outside vortex becomes significant, and the longitudinal gradient maximum occurs near the vortex edge. The ozone experiences a severe depletion inside the polar vortex, especially in September and October. The latitudinal distribution of ozone outside vortex is inhomogeneous, featuring a maximum within $90-180^{\circ} \mathrm{E}$. This zonal difference may be caused by latitudinal inhomogeneity of Brewer-Dobson transportation.

\subsection{Relationships between Polar Vortex and Ozone Depletion} in Temporal Variation. In this section, we explore the relationships between polar vortex and ozone depletion in temporal variation. Polar vortex parameters include polar vortex area, polar vortex strength, and polar vortex breakup time as mentioned above, and ozone parameter is the averaged total column ozone within the polar vortex based on the criterion PV contour (-28.8 PVU) on $550 \mathrm{~K}$ isentropic surface.

Figure 4 shows the seasonal variation of averaged total column ozone within the polar vortex from 1979 to 2016 . We only focus on the variation of ozone during the period of the stable vortex (May to October). The ozone depletion in austral spring (September-October, $\mathrm{SO}$ ) can clearly be seen in Figure 4, and the most severe ozone depletion occurs in the mid-1990s with the value less than 160 DU. Besides the obvious seasonal cycle, the spring total column ozone within the polar vortex shows a strong interannual variation, with a maximum of 314.4 DU in October 1979 and a minimum of 132.0 DU in September 1995. Larger ozone variations can be seen after the mid-1990s, with extreme high values in 2002 and 2010 and extreme low values in 2003, 2006, 2008, 2011, and 2015. The values in this figure are generally lower than the results in previous study [17] because the ozone was calculated within the polar vortex in this work, instead of the whole Antarctic region $\left(60^{\circ}-90^{\circ}\right)$. In other words, we investigate the severe ozone depletion occurrence in the interior of polar vortex.

As mentioned above, since the most severe ozone depletion happens in austral spring (SO), we analyze the relationship between polar vortex and ozone depletion in this season with three vortex parameters described in Section 2.

Figure 5 shows the interannual variations of total column zone within the polar vortex, the polar vortex area, strength, and breakup time for the period 1979-2016. Figure 5(a) revealed that the ozone within the polar vortex in austral spring experiences a severe depletion before the mid-1990s and recovers gradually in the 2000s, owing to the implementation of international protocols on the control of ozonedepleting substances. Figure 5(b) presents the interannual change of polar vortex area in September, October, and SO averaged, respectively. The variations of polar vortex area in 

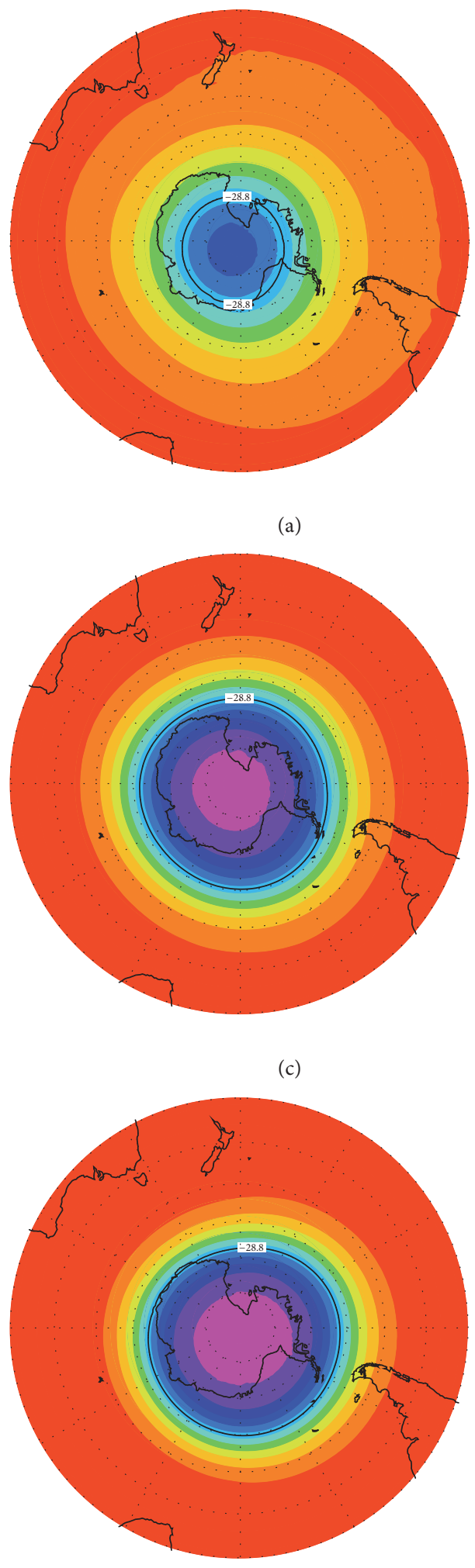

(a)

(c)

(e)

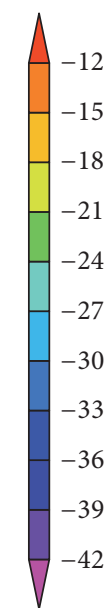

Unit: PVU

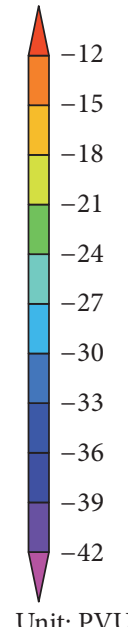

Unit: PVU

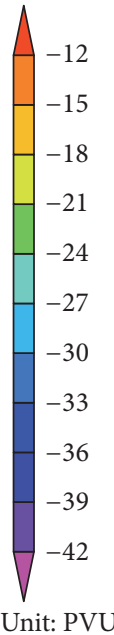

Unit: PVU

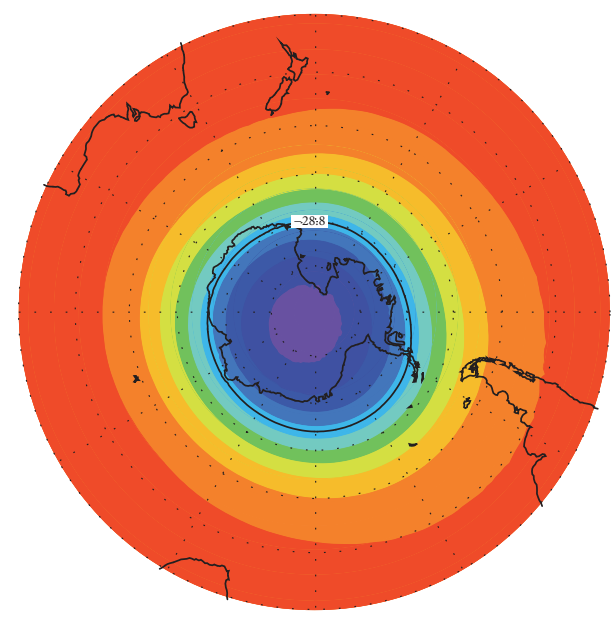

(b)

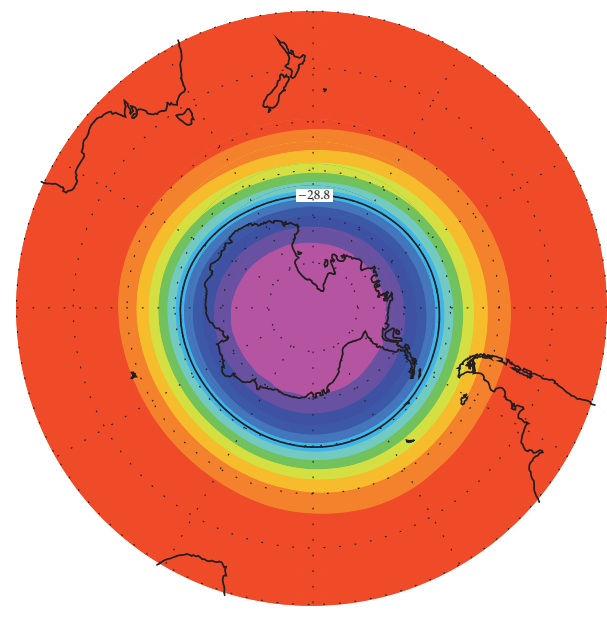

(d)

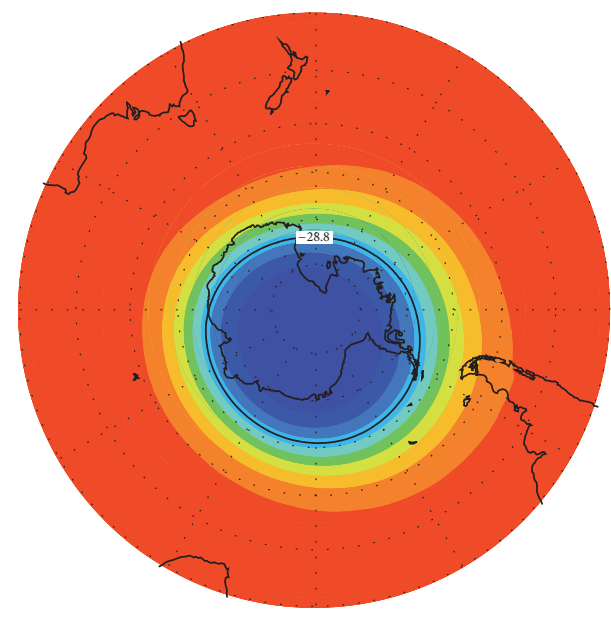

(f)

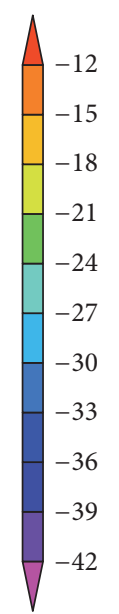

Unit: PVU

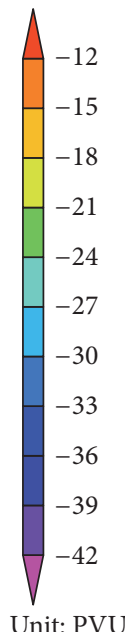

Unit: PVU

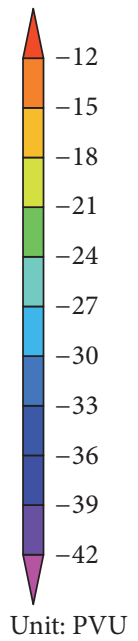

Unit: PVU

FIGURE 1: Spatial distributions of the 38-year (1979-2016) potential vorticity (units: PVU) climatology on 550 K isentropic surface in (a) May, (b) June, (c) July, (d) August, (e) September, and (f) October. The black solid based on criterion PV contour (-28.8 PVU) represents the vortex edge. 


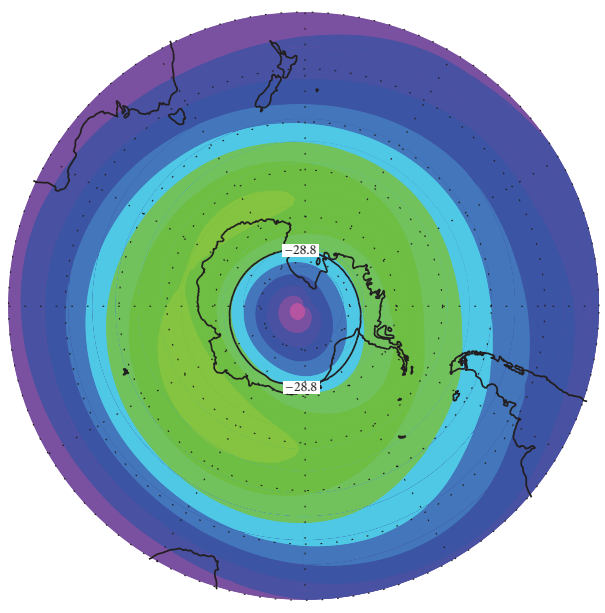

(a)

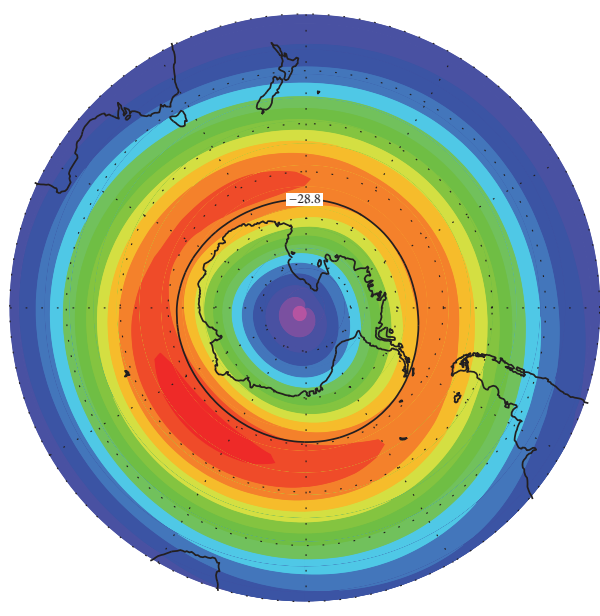

(c)

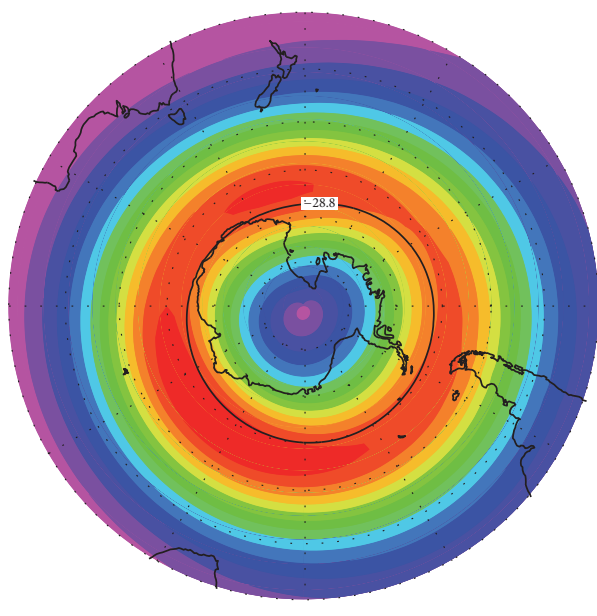

(e)

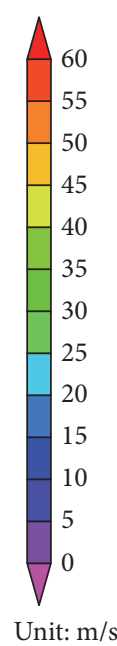

Unit: $\mathrm{m} / \mathrm{s}$

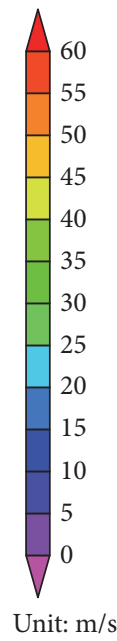

Unit: $\mathrm{m} / \mathrm{s}$

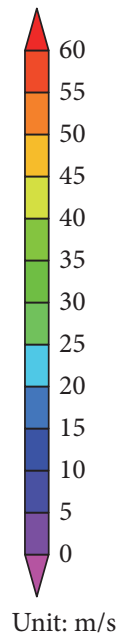

Unit: $\mathrm{m} / \mathrm{s}$

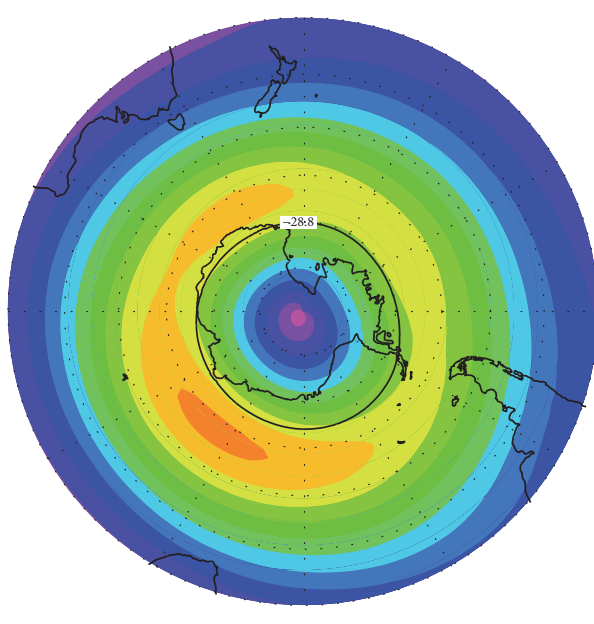

(b)

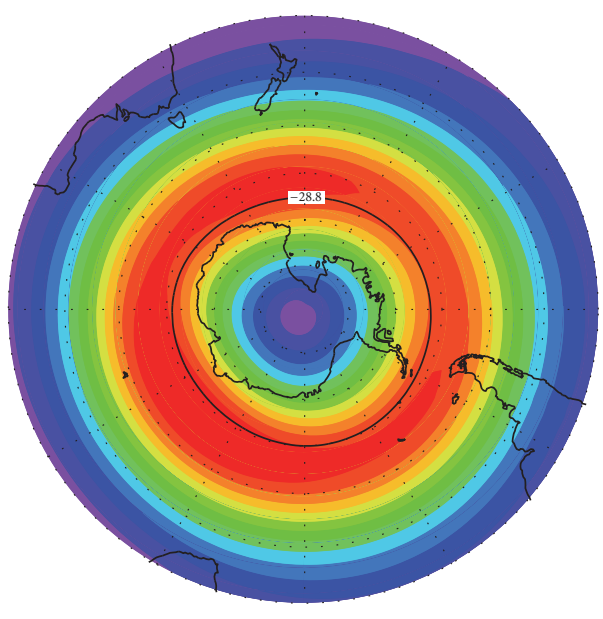

(d)

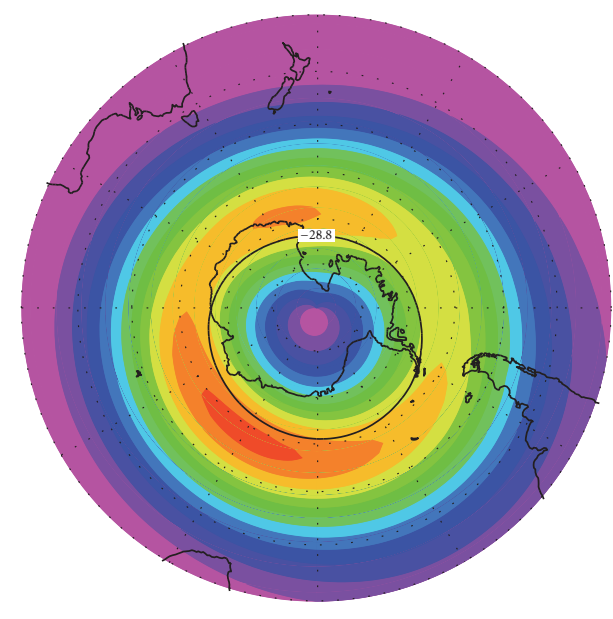

(f)

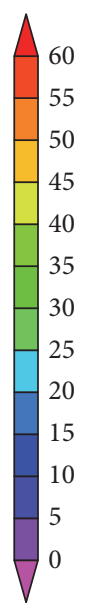

Unit: $\mathrm{m} / \mathrm{s}$

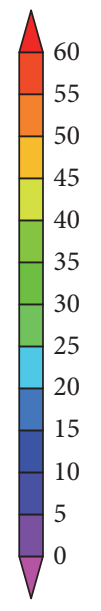

Unit: $\mathrm{m} / \mathrm{s}$

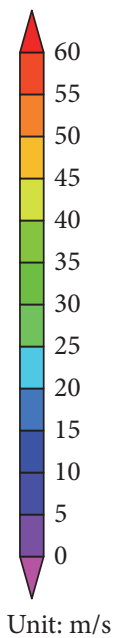

Unit: $\mathrm{m} / \mathrm{s}$

FIGURE 2: Spatial distributions of the 38-year (1979-2016) zonal wind (units: m/s) climatology on $550 \mathrm{~K}$ isentropic surface in (a) May, (b) June, (c) July, (d) August, (e) September, and (f) October. The black solid based on criterion PV contour (-28.8 PVU) represents the vortex edge. 


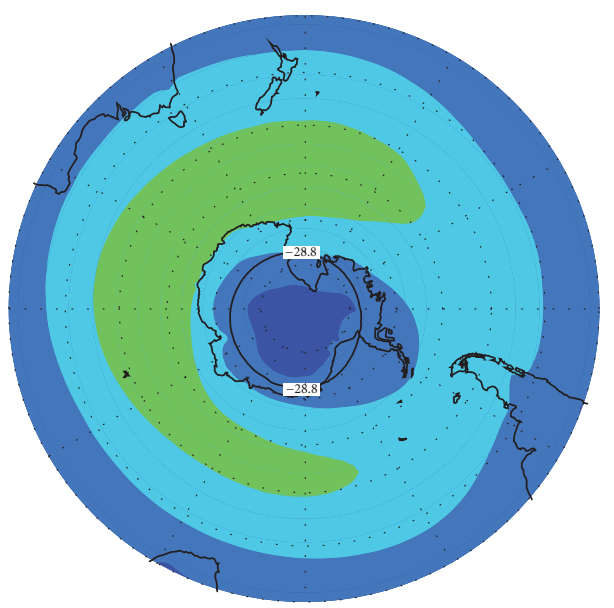

(a)

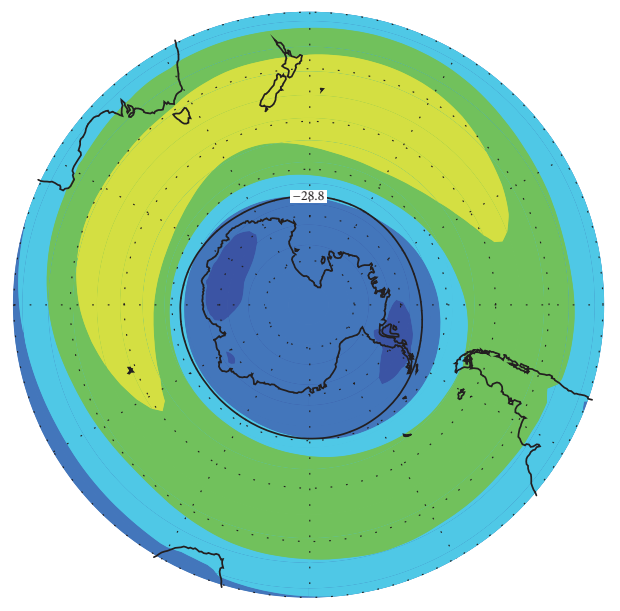

(c)

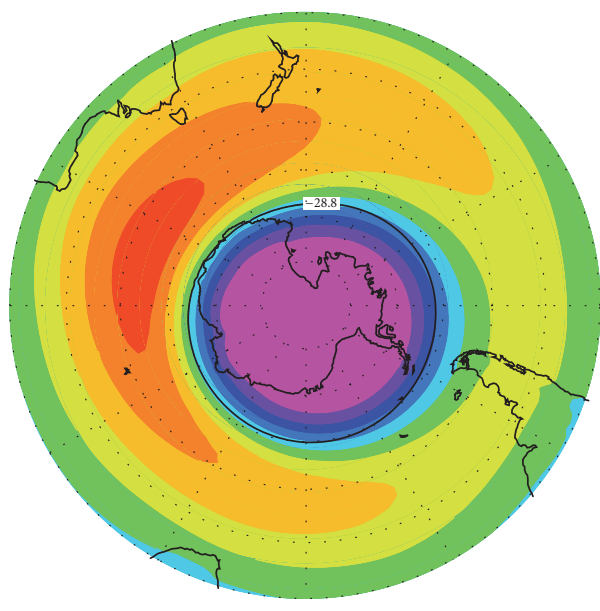

(e)

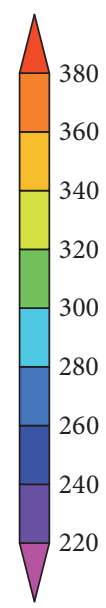

Unit: DU

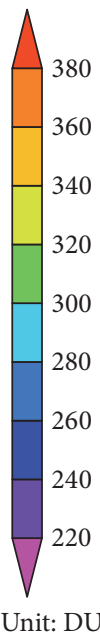

Unit: DU

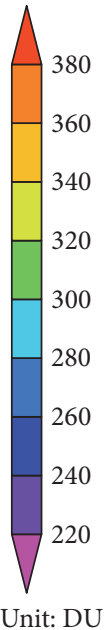

Unit: DU

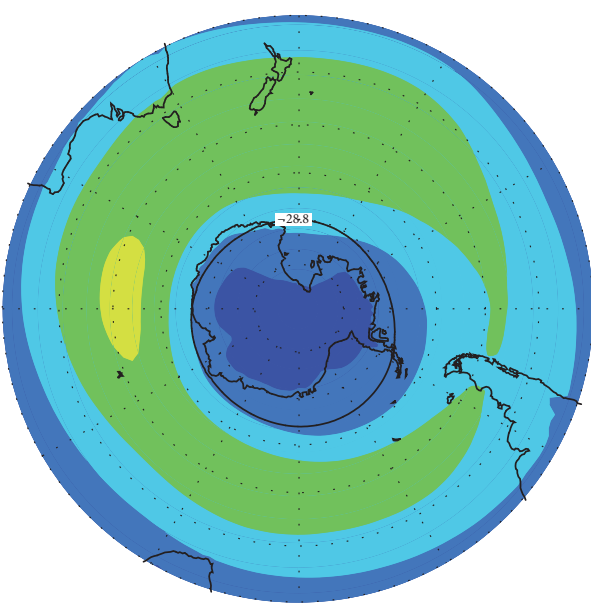

(b)

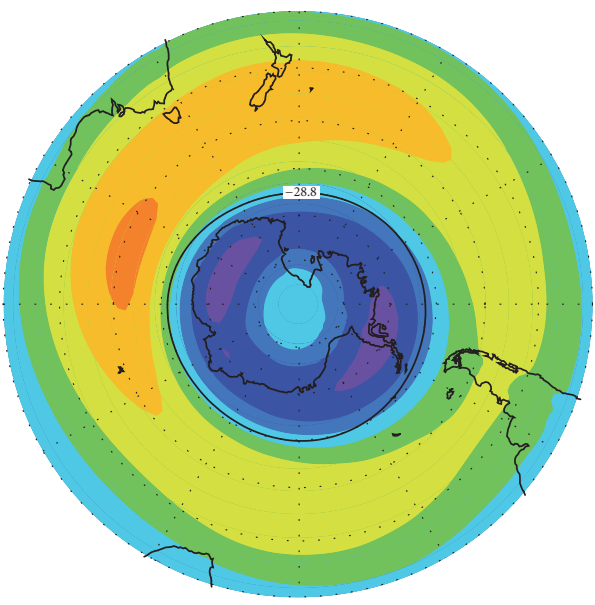

(d)

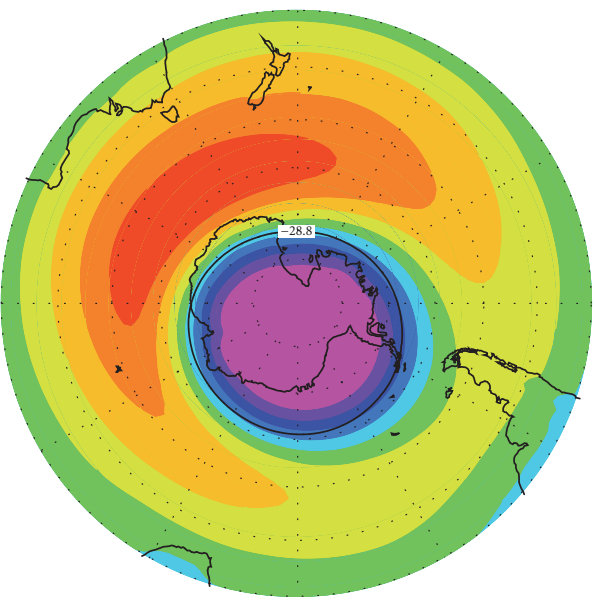

(f)

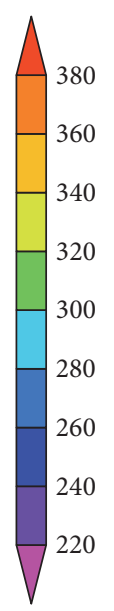

Unit: DU

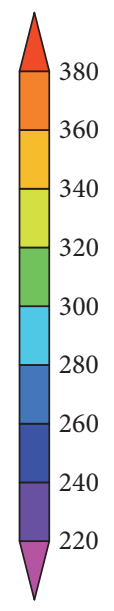

Unit: DU

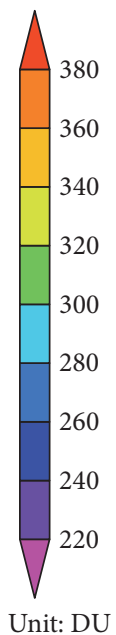

Unit: DU

FIGURE 3: Spatial distributions of the 38-year (1979-2016) total column ozone (units: DU) in (a) May, (b) June, (c) July, (d) August, (e) September, and (f) October. The black solid based on criterion PV contour (-28.8 PVU) represents the vortex edge. 


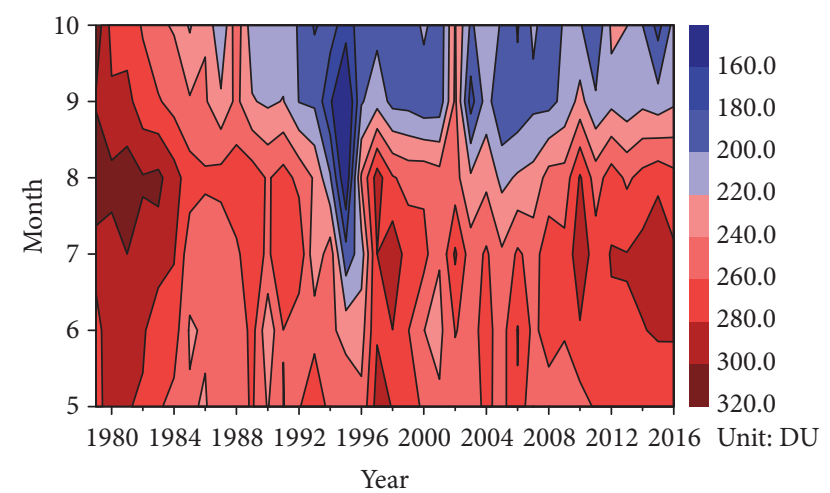

FIGURE 4: Monthly variation of averaged total column ozone (units: DU) within the polar vortex from 1979 to 2016. The contour interval is $20 \mathrm{DU}$ and the values less than $220 \mathrm{DU}$ (Antarctic ozone hole threshold) are shaded with blue color.

two months are basically similar, but the area in October is entirely smaller than September because of the shrinkage of polar vortex. SO averaged polar vortex area reaches the maximum with a value of $7 \times 10^{5} \mathrm{~km}^{2}$ in 2015 and the minimum in the value of $3.4 \times 10^{5} \mathrm{~km}^{2}$ in 2002 . According to Figure 5(f), the larger polar vortex area events (greater than +1.0 SD) occur in 1987, 1998, 2001, 2003, 2006, and 2015, while the smaller area events (less than -1.0 SD) happen in 1986, 1988, 2002, and 2012. Figure 5(c) presents the interannual change of polar vortex strength in September, October, and SO averaged, respectively. The variations of polar vortex strength in two months are also similar, but the strength in October is entirely weaker than September because of the decay of polar vortex. SO averaged polar vortex strength reaches the maximum with a value of $58.2 \mathrm{~m} / \mathrm{s}$ in 1993 and the minimum with a value of $30.5 \mathrm{~m} / \mathrm{s}$ in 2002 . Figure $5(\mathrm{~g})$ presents that the stronger polar vortex events (greater than +1.0 SD) occur in 1993, 1998, and 2001, while the weaker events (less than -1.0 SD) occur in 1981, 1988, 2002, 2012, and 2013. Figure 5(d) indicates the interannual variation of polar vortex breakup time during the period of 1979-2016. Before the mid-1990s, the breakup time has a significant delay trend, which is consistent with a significant decrease trend in the variations of total column ozone during the same period. Figure 5(h) shows that the later vortex breakup events (greater than +1.0 SD) occur in the years of 1995, 1996, 1998, 1999, 2001, 2008, and 2010, and the earlier breakup events (less than -1.0 SD) happen in 1979, 1988, 2002, 2012, 2013, and 2016. The later polar vortex breakup events are basically consistent with the low-value of total column ozone years, and vice versa. In a word, the relationship between ozone depletion and vortex breakup time seems better than other two polar vortex parameters (area and strength) qualitatively.

We further present the scatter plot between the three polar vortex parameters and averaged total column ozone in Figure 6 . The correlation coefficients are $-0.57,-0.68$, and -0.76 between averaged total column ozone and polar vortex area, strength, and breakup time, respectively; all correlations are significant $(\alpha 0.01)$. Results in Figure 6 indicated that the larger, stronger, or later breakup time polar vortex is highly related to the ozone depletion, which is supported by previous studies $[3,32]$. Since there is less air exchange between Antarctic and the southern midlatitudes than that between Arctic and the northern midlatitudes, ozone depletion over the Antarctic is much more severe than that over the Arctic [33]. The chemistry of the Antarctic polar vortex has created severe ozone depletion. The nitric acid in polar stratospheric clouds reacts with chlorofluorocarbons to form chlorine, which catalyzes the photochemical destruction of ozone [3, 34]. Meanwhile, chlorine concentrations build up during the polar winter, and consequent ozone destruction is greatest when the sunlight returns in polar winter [35]. Accordingly, the breakup time of polar vortex during austral spring is of much concern to study the ozone depletion subject. As we expect, results also display the largest correlation between polar vortex breakup time and ozone in Figure 6(c). Therefore, we analyze the relationship between polar vortex breakup time and ozone depletion in depth for the next step via the difference composite.

Polar vortex breakup time index (referred to as PVBTI) is introduced in Figure 5(h); the high-value PVBTI refers to later breakup event and the low-value PVBTI means earlier breakup event. Considering the polar vortex breakup time concentrating in austral spring while the most severe ozone depletion occurs in September and October, we focus on the differences in this period dramatically. The total column ozone within the polar vortex in September and October is identified through the investigation of differences in highvalue (greater than $+1.0 \mathrm{SD}$ ) and low-value (less than -1.0 SD) PVBTI years in Figure 7. Figure 7(a) shows the total column ozone anomalies in high-value PVBTI years, when the polar vortex breaks up later. The result indicates that the negative anomalies of total column ozone cover the whole Antarctic. However, compared to Figure 7(a), larger areas with significant positive anomalies can be found in low-value PVBTI years (Figure 7(b)). Figure 7(c) shows the total column ozone difference between high-value and low-value PVBTI years. The most severe depletion with significant negative anomalies occurs over east Antarctica, lying on the Indian Ocean side of the continent. Results reveal that the earlier breakup of polar vortex can effectively inhibit the ozone depletion in the Antarctic stratosphere, as previous studies described [17, $36,37]$. The shrinkage or erosion of the polar vortex due to planetary-wave breaking is possibly responsible for the ozone recovery over Antarctica by importing ozone from the midlatitudes through lateral mixing or the Brewer-Dobson circulation [38].

\section{Discussion and Conclusions}

This work examines the relationships between ozone depletion and polar vortex in terms of its area, strength, and breakup time in the Antarctic stratosphere during the period 1979-2016 and discusses possible mechanisms behind the relationships. We first explore spatial distributions of the 38year (1979-2016) potential vorticity, zonal wind, and total column ozone climatology on $550 \mathrm{~K}$ isentropic surface from May to October and the monthly variation of total column ozone within the polar vortex based on criterion PV contour 

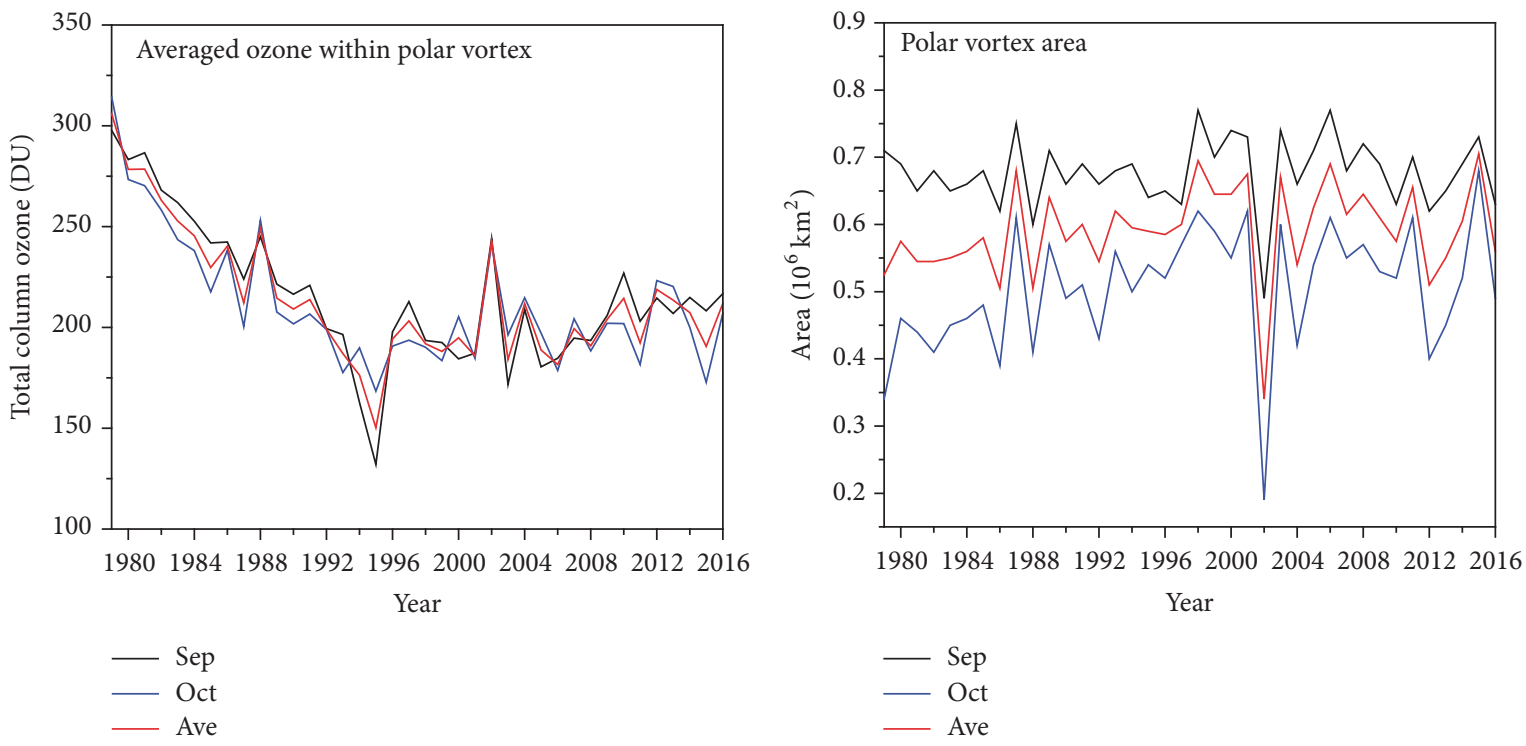

(a)
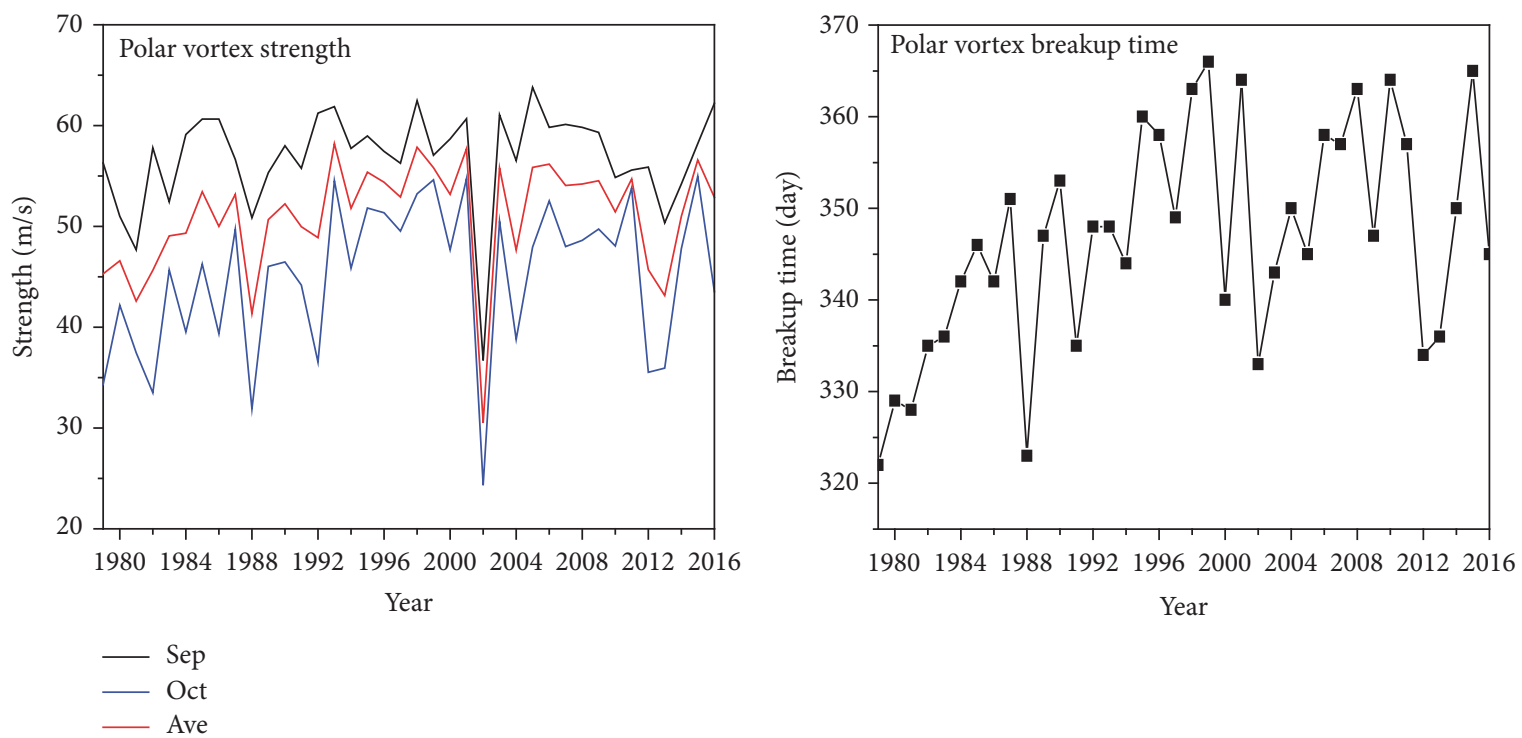

(c)

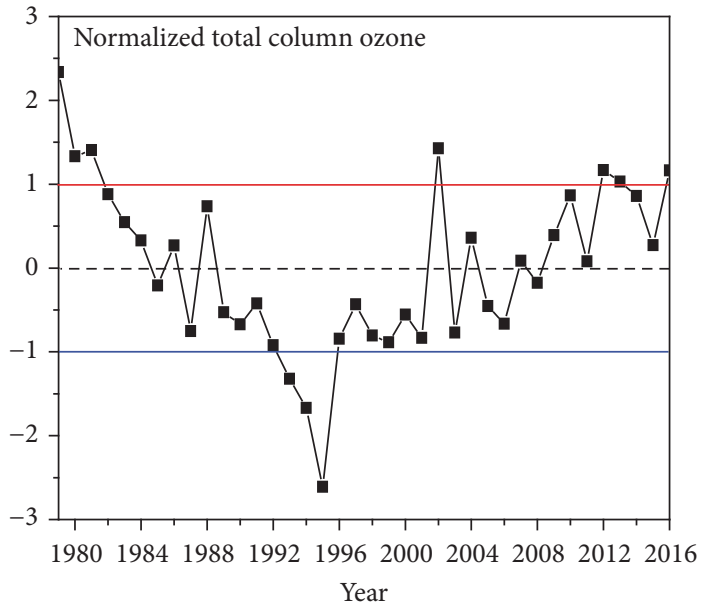

(d)

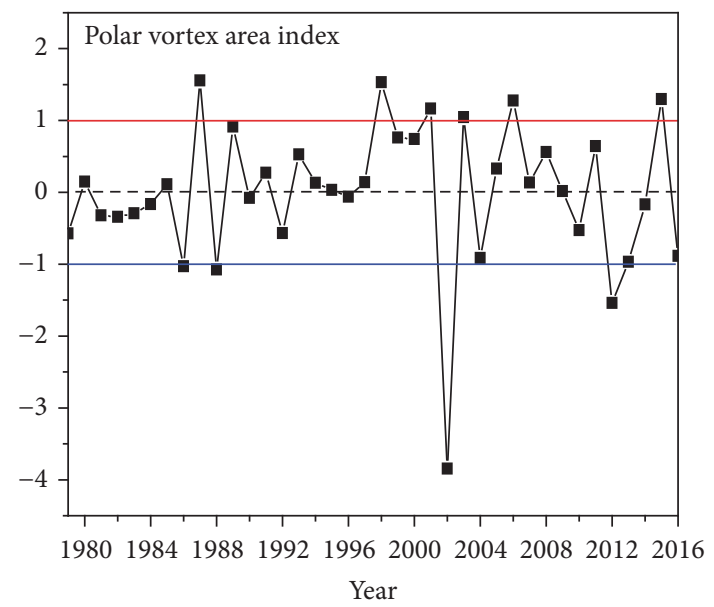

(e)

(f)

FIgUre 5: Continued. 


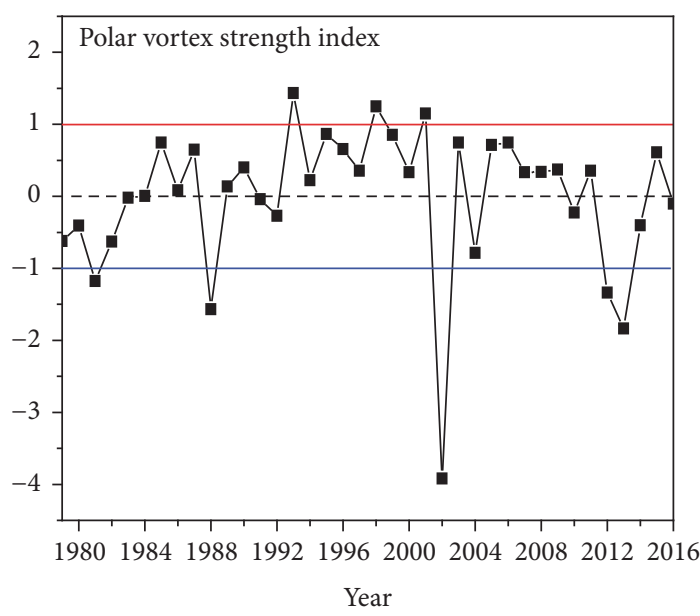

(g)

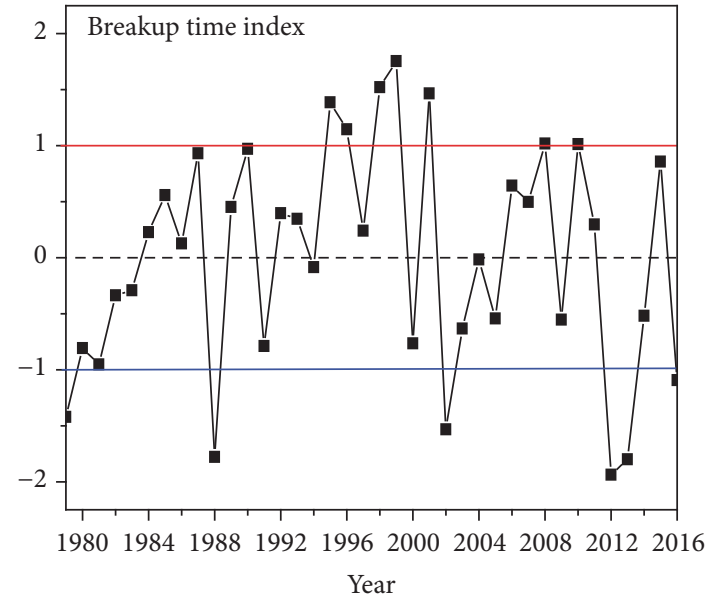

(h)

FIGURE 5: (a) The interannual variations of total column ozone in the interior of polar vortex (units: DU), (b) polar vortex area (units: $10^{6} \mathrm{~km}^{2}$ ), and (c) polar vortex strength (units: $\mathrm{m} / \mathrm{s}$ ) in September (black curve), October (blue curve), and SO averaged (red curve), respectively. (d) The polar vortex breakup time (units: day) for the period 1979-2016. (e)-(h) Time series of detrend and normalized ozone, vortex area, strength, and breakup time index during the period 1979-2016. Values less than -1.0 (blue line) or more than +1.0 (red line) are used to distinguish the vortex area, smaller/larger; strength, weaker/stronger; and breakup time earlier/later years, respectively.

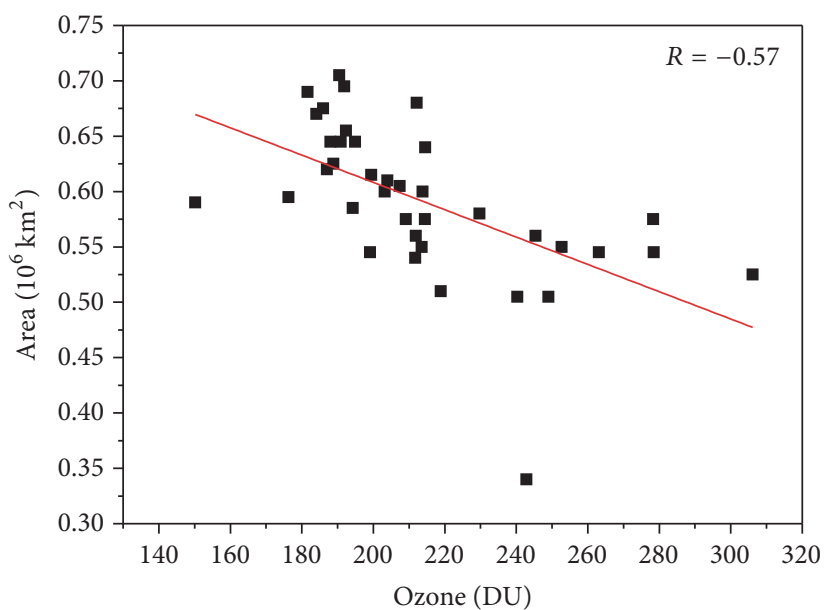

(a)

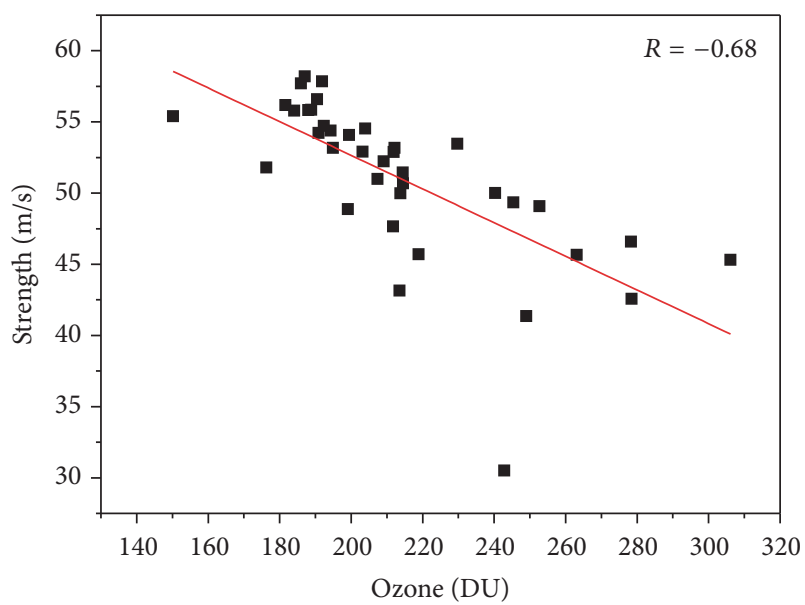

(b)

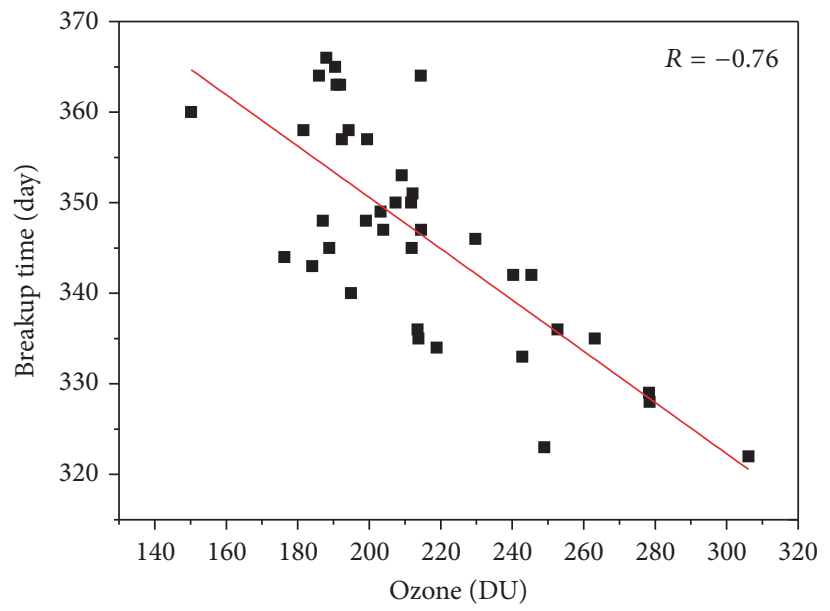

(c)

Figure 6: Scatterplots of (a) polar vortex area, (b) polar vortex strength, and (c) polar vortex breakup time versus total column ozone within the polar vortex for 38-year (1979-2016) record. The linear correlation coefficients are given in the top right of each plot. 


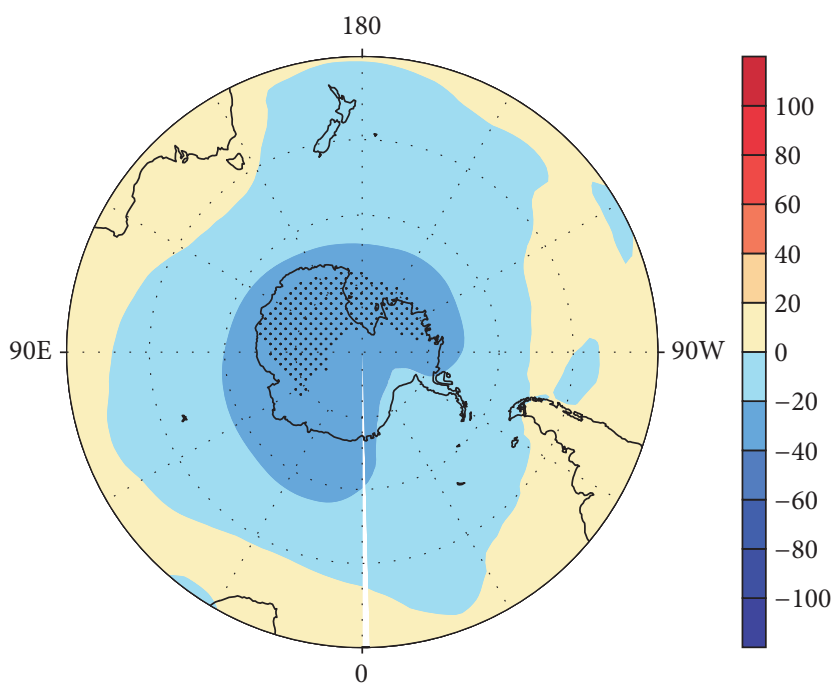

(a)

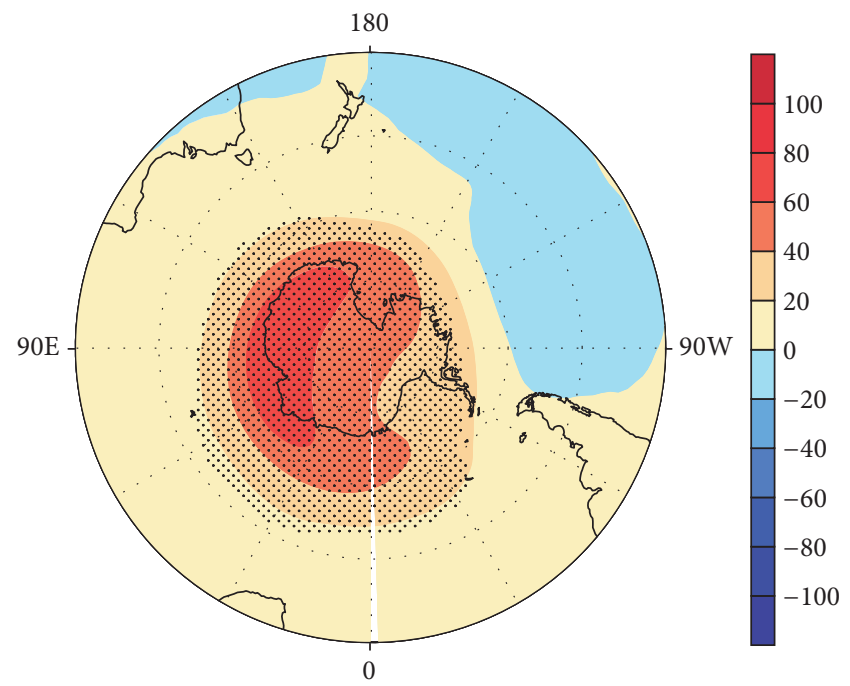

(b)

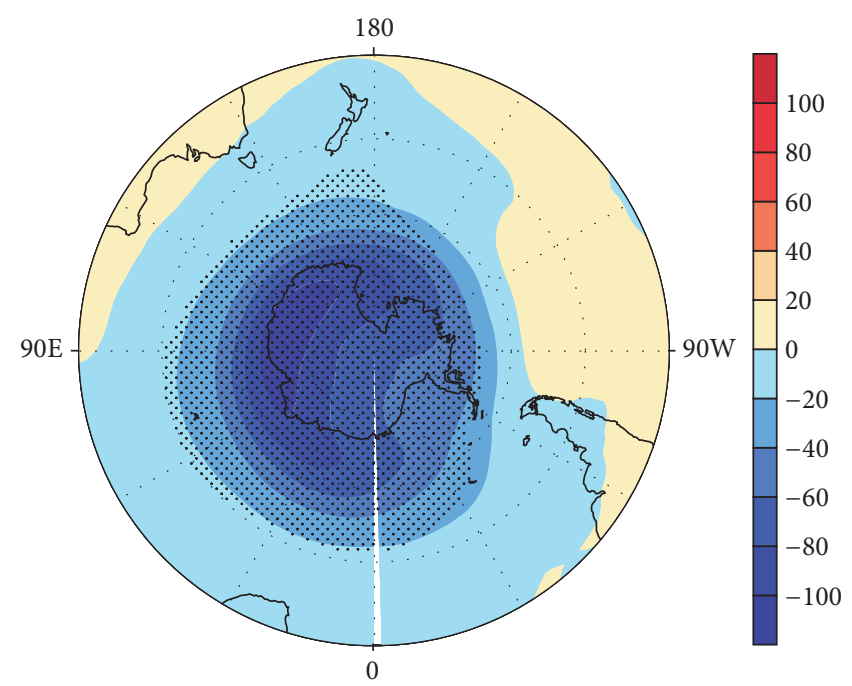

(c)

Figure 7: Composite anomalies of September-October total column ozone (units: DU) in (a) high-value PVBTI years and (b) low-value PVBTI years. (c) Composite difference of total column ozone (units: DU) between high-value and low-value PVBTI years. Dotted areas show significant changes at $95 \%$ level, estimated by local Student's $t$-test.

(-28.8 PVU). In addition, we investigate the relationships between polar vortex and ozone depletion via the correlation and linear regression analysis. We further study the variation of ozone depletion in later and earlier polar vortex breakup time based on a composite analysis. The major conclusions can be summarized as follows:

(1) The morphological changes of polar vortex can impact the horizontal distribution of ozone, and the maximum longitudinal gradient occurs at the edge of polar vortex; the ozone within the polar vortex experiences a severe depletion in spring.

(2) The Antarctic polar vortex exists stably from May to October despite the large interannual variations, while the most severe ozone depletion happens in austral spring, September-October.
(3) The larger, stronger, and later breakup time polar vortex is highly related to the ozone depletion with the correlation coefficients of $-0.57,-0.68$, and -0.76 between averaged total column ozone and polar vortex area, strength, and breakup time, respectively.

(4) The breakup time of polar vortex plays an important role in the relation between polar vortex and ozone depletion with the highest-value correlation coefficient among three polar vortex parameters.

(5) The most severe depletion with significant negative anomalies occurs over east Antarctica, lying on the Indian Ocean side of the Antarctica continent.

The relationship between polar vortex and ozone depletion is mutual and complicated. The later breakup of polar 
vortex could effectively intensify the Antarctic ozone depletion, owing to the longer longevity of lower temperature and less ozone supplement from midlatitudes to polar region. On the other hand, the dramatic ozone loss could have caused cooling, which in turn strengthens the polar vortex and makes the vortex break up later [36]. Possible mechanisms for the relationship should be investigated, through quantitative evaluation of the dynamic effect of polar vortex on ozone depletion and the thermal effect of ozone on polar vortex evolution.

\section{Conflicts of Interest}

The authors declare that they have no conflicts of interest.

\section{Acknowledgments}

Funding for this project was provided by the projects entitled "Comprehensive Evaluation of Polar Areas in Global and Regional Climate Changes" [CHINARE2015-2019] and "Polar Environment Comprehensive Investigation and Assessment" [CHINARE2015-2019] and the Program for Scientific Research Start-Up Funds of Guangdong Ocean University entitled "Air-Sea Interaction and Data Assimilation" and "Effect of the Tropical Sea Surface Temperature Anomaly on the Polar Stratosphere."

\section{References}

[1] J. Van der Leun, X. Tang, and M. Tevini, "Environmental effects of ozone depletion: 1994 assessment," AMBIO-STOCKHOLM, vol. 24, pp. 138-138, 1995.

[2] M. Norval, A. Cullen, F. De Gruijl, J. Longstreth, Y. Takizawa et al., "The effects on human health from stratospheric ozone depletion and its interactions with climate change," Photochemical \& Photobiological Sciences, vol. 6, pp. 232-251, 2007.

[3] M. R. Schoeberl and D. L. Hartmann, "The dynamics of the stratospheric polar vortex and its relation to springtime ozone depletions," Science, vol. 251, no. 4989, pp. 46-52, 1991.

[4] J. G. Titus, Effects of Changes in Stratospheric Ozone and Global Climate: Sea Level Rise, vol. 4, US Environmental Protection Agency, 1986.

[5] J. C. Farman, B. G. Gardiner, and J. D. Shanklin, "Large losses of total ozone in Antarctica reveal seasonal $\mathrm{ClO} x / \mathrm{NOx}$ interaction," Nature, vol. 315, no. 6016, pp. 207-210, 1985.

[6] R. S. Stolarski, A. J. Krueger, M. R. Schoeberl, R. D. Mcpeters, P. A. Newman, and J. C. Alpert, "Nimbus 7 satellite measurements of the springtime Antarctic ozone decrease," Nature, vol. 322, no. 6082 , pp. 808-811, 1986.

[7] R. B. Pierce and T. D. A. Fairlie, "Chaotic advection in the stratosphere: Implications for the dispersal of chemically perturbed air from the polar vortex," Journal of Geophysical Research: Atmospheres, vol. 98, pp. 18589-18595, 1993.

[8] E. R. Nash, P. A. Newman, J. E. Rosenfield, and M. R. Schoeberl, "Schoeberl, M.R. An objective determination of the polar vortex using Ertel's potential vorticity," Journal of Geophysical Research: Atmospheres, vol. 101, pp. 9471-9478, 1996.

[9] T. J. Duck, J. A. Whiteway, and A. I. Carswell, "Lidar observations of gravity wave activity and Arctic stratospheric vortex core warming," Geophysical Research Letters, vol. 25, no. 15, pp. 2813-2816, 1998.

[10] D. W. J. Thompson, M. P. Baldwin, and J. M. Wallace, "Stratospheric connection to Northern Hemisphere wintertime weather: Implications for prediction," Journal of Climate, vol. 15, no. 12, pp. 1421-1428, 2002.

[11] J. Li, K. Fan, J. Xu, A. M. Powell, and F. Kogan, "The effect of preceding wintertime Arctic polar vortex on springtime NDVI patterns in boreal Eurasia, 1982-2015," Climate Dynamics, pp. 1-13, 2016.

[12] Z. Wang and Y. Ding, "Impacts of the long-term change of the summer Asian polar vortex on the circulation system and the water vapor transport in East Asia," Chinese J Geophys, vol. 52, pp. 20-29, 2009.

[13] D. W. Waugh and L. M. Polvani, "Stratospheric polar vortices," Geophysical Monograph Series, vol. 190, no. 1, pp. 43-57, 2010.

[14] M. H. Proffitt, J. J. Margitan, K. K. Kelly, M. Loewenstein, J. R. Podolske, and K. R. Chan, "Ozone loss in the Arctic polar vortex inferred from high-altitude aircraft measurements," Nature, vol. 347, no. 6288, pp. 31-36, 1990.

[15] J. G. Anderson, D. W. Toohey, and W. H. Brune, "Free radicals within the Antarctic vortex: the role of CFCs in Antarctic ozone loss," Science, vol. 251, no. 4989, pp. 39-46, 1991.

[16] B. Hassler, G. E. Bodeker, S. Solomon, and P. J. Young, "Changes in the polar vortex: Effects on Antarctic total ozone observations at various stations," Geophysical Research Letters, vol. 38, no. 1, Article ID L01805, 2011.

[17] L. Zhou, Y. Zhang, and S. Ma, "Continuous ozone depletion over Antarctica after 2000 and its relationship with the polar vortex," Journal of Meteorological Research, vol. 28, no. 1, pp. 162-171, 2014.

[18] N. Butchart and E. E. Remsberg, "The area of the stratospheric polar vortex as a diagnostic for tracer transport on an isentropic surface." Journal of the Atmospheric Sciences, vol. 43, no. 13, pp. 1319-1339, 1986.

[19] C. I. Garfinkel, D. L. Hartmann, and F. Sassi, “Tropospheric precursors of anomalous northern hemisphere stratospheric polar vortices," Journal of Climate, vol. 23, no. 12, pp. 3282-3299, 2010.

[20] P. Berrisford, D. Dee, K. Fielding, M. Fuentes, P. Kallberg et al., “The ERA-interim archive," ERA report series, pp. 1-16, 2009.

[21] D. P. Dee, S. M. Uppala, and A. J. Simmons, “The ERA-Interim reanalysis: configuration and performance of the data assimilation system," Quarterly Journal of the Royal Meteorological Society, vol. 137, no. 656, pp. 553-597, 2011.

[22] M. E. McIntyre and T. N. Palmer, "The 'surf zone' in the stratosphere," Journal of Atmospheric and Terrestrial Physics, vol. 46, no. 9, pp. 825-849, 1984.

[23] L. R. Lait, "An alternative form for potential vorticity," Journal of the Atmospheric Sciences, vol. 51, pp. 1754-1759, 1994.

[24] A. Karpetchko, E. Kyrö, and B. M. Knudsen, "Arctic and Antarctic polar vortices 1957-2002 as seen from the ERA-40 reanalyses," Journal of Geophysical Research Atmospheres, vol. 110, no. 21, Article ID D21109, pp. 1-14, 2005.

[25] M. R. Schoeberl, L. R. Lait, P. A. Newman, and J. E. Rosenfield, "The structure of the polar vortex," Journal of Geophysical Research, vol. 97, no. 8, pp. 7859-7882, 1992.

[26] D. W. Waugh and W. J. Randel, "Climatology of Arctic and Antarctic polar vortices using elliptical diagnostics," Journal of the Atmospheric Sciences, vol. 56, no. 11, pp. 1594-1613, 1999. 
[27] V. Limpasuvan, D. L. Hartmann, D. W. J. Thompson, K. Jeev, and Y. L. Yung, "Stratosphere-troposphere evolution during polar vortex intensification," Journal of Geophysical Research Atmospheres, vol. 110, no. 24, Article ID D24101, pp. 1-15, 2005.

[28] K. Walter and H. F. Graf, “The North Atlantic variability structure, storm tracks, and precipitation depending on the polar vortex strength," Atmospheric Chemistry and Physics, vol. 5, no. 1, pp. 239-248, 2005.

[29] R. Ren and M. Cai, "Polar vortex oscillation viewed in an isentropic potential vorticity coordinate," Advances in Atmospheric Sciences, vol. 23, no. 6, pp. 884-900, 2006.

[30] J. Rao, R. Ren, and Y. Yang, "Parallel comparison of the northern winter stratospheric circulation in reanalysis and in CMIP5 models," Advances in Atmospheric Sciences, vol. 32, no. 7, pp. 952-966, 2015.

[31] G. L. Manney, R. W. Zurek, M. E. Gelman, A. J. Miller, and R. Nagatani, "The anomalous Arctic lower stratospheric polar vortex of 1992-1993," Geophysical Research Letters, vol. 21, no. 22, pp. 2405-2408, 1994.

[32] G. Hansen and M. P. Chipperfield, "Ozone depletion at the edge of the Arctic polar vortex 1996/1997," Journal of Geophysical Research: Atmospheres, vol. 104, pp. 1837-1845, 1999.

[33] K. Mohanakumar, Stratosphere Troposphere Interactions: an Introduction, Springer Science \& Business Media, 2008.

[34] P. Wadhams, J. A. Dowdeswell, and A. Schofield, Arctic and Environmental Change, vol. 352, CRC Press, 1997.

[35] R. Müller, Tracer-tracer Relations as a Tool for Research on Polar Ozone Loss, vol. 58, Forschungszentrum Jülich, 2010.

[36] S. Zhou, M. E. Gelman, A. J. Miller, and J. P. McCormack, "An Inter-hemisphere comparison of the persistent stratospheric polar vortex," Geophysical Research Letters, vol. 27, no. 8, pp. 1123-1126, 2000.

[37] D. W. Waugh and P.-P. Rong, "Interannual variability in the decay of lower stratospheric Arctic vortices," Journal of the Meteorological Society of Japan, vol. 80, no. 4 B, pp. 997-1012, 2002.

[38] S. Montzka, S. Reimann, A. Engel, K. Kruger, W. Sturges et al., "Scientific assessment of ozone depletion: 2010," Global Ozone Research and Monitoring Project-Report, vol. 51, 2011. 

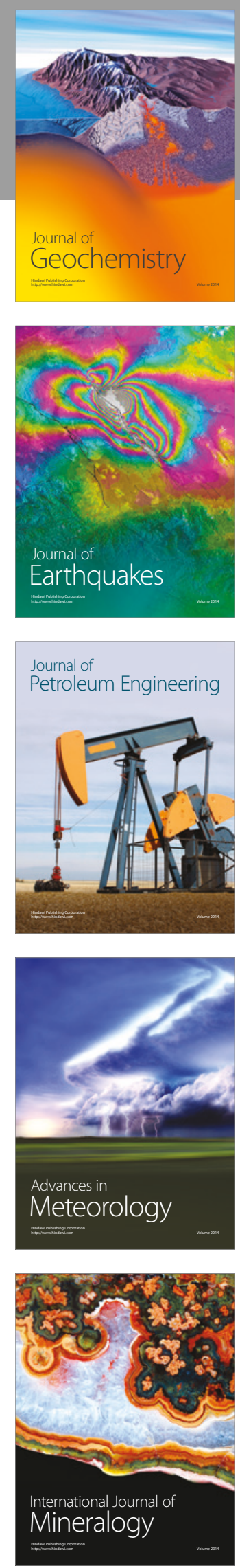
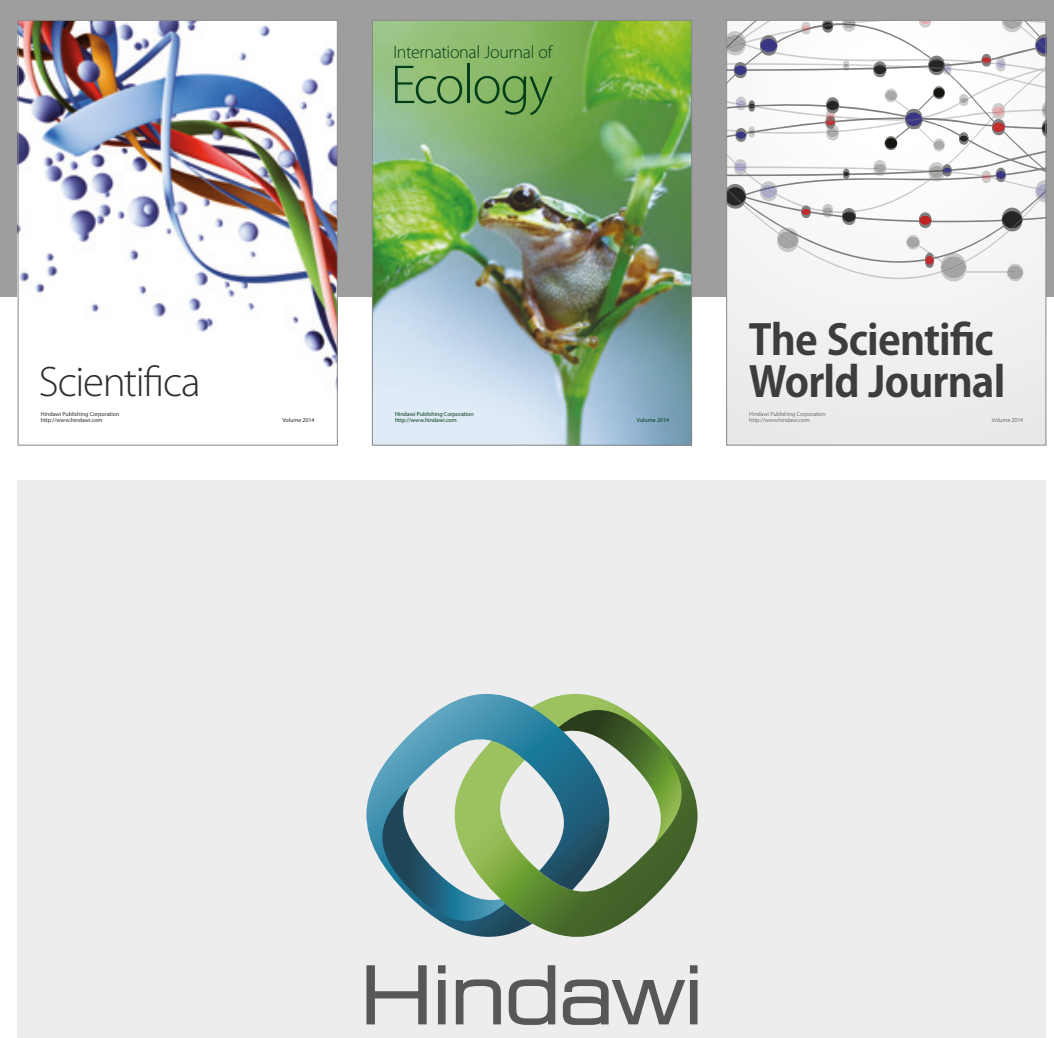

Submit your manuscripts at

https://www.hindawi.com
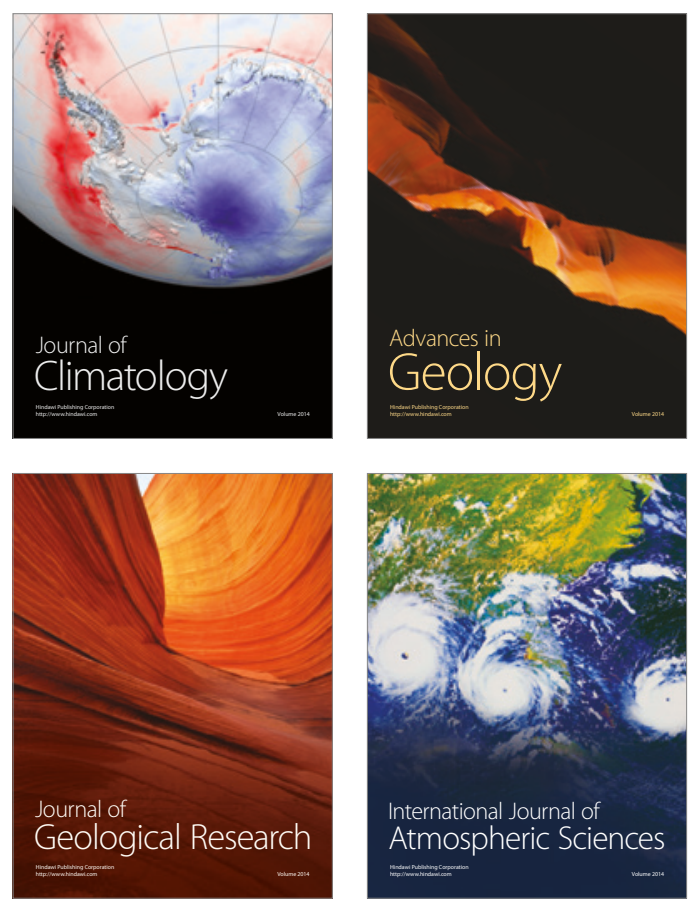

The Scientific

World Journal
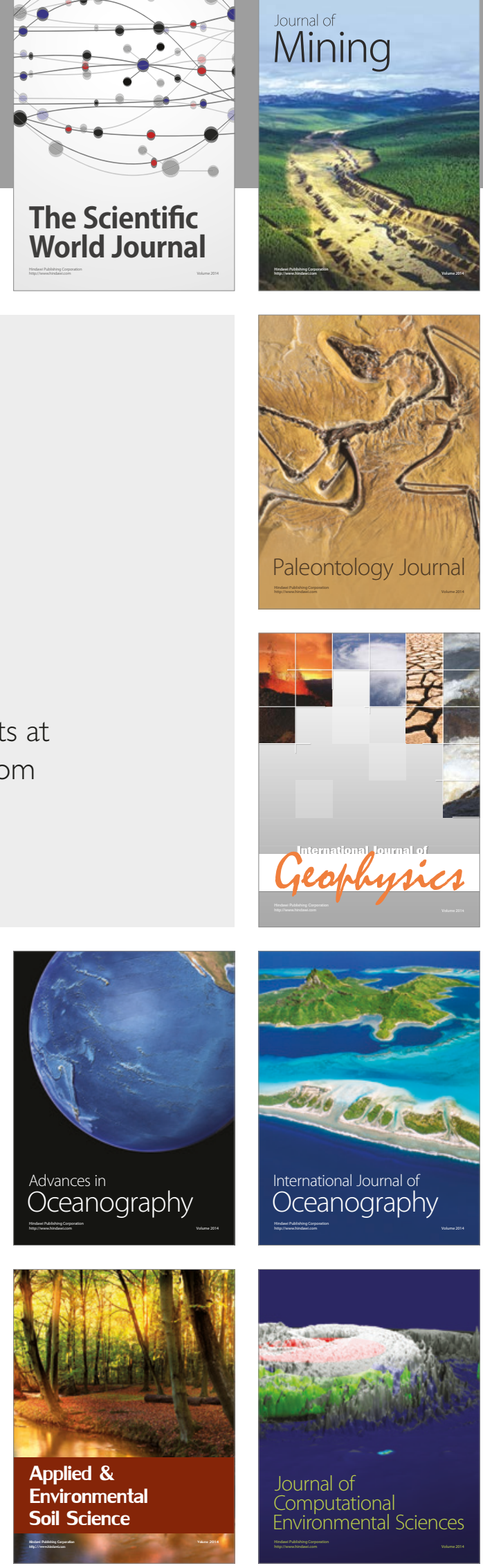